\title{
Análise Econômica-Financeira em Cooperativas: um estudo de caso na CAMSUL
}

\author{
Economic and Financial Analysis on Cooperative: a case study in CAMSUL
}

\begin{abstract}
Resumo
As demonstrações financeiras constituem-se em um importante instrumento no auxílio da administração moderna, $e$ tem como objetivo principal gerar informações para embasar as decisões a serem tomadas. As pessoas, jurídicas ou físicas, buscam gerenciar seus recursos, com o intuito de descobrir os custos e despesas, de produção ou financeiros. Para tanto, faz-se necessário uma análise de todos os pontos onde pode se obter uma redução dos custos, com a finalidade de conseguir uma melhora nas suas receitas líquidas. Diante disso, o presente estudo de caso buscou analisar qual a situação econômica financeira da CAMSUL no período de 2010 a 2014 por meio do cálculo dos índices de liquidez, rentabilidade e endividamento e por meio da análise vertical e horizontal. Os resultados apresentados pela CAMSUL demonstraram que a cooperativa está se desenvolvendo nos últimos anos e ampliando sua atuação no ramo. Durante a elaboração do trabalho, foram detectadas algumas limitações como a escassez de bibliografia específica sobre a análise econômica financeira de cooperativas, o que restringiu a pesquisa pela falta de maiores informações a respeito do tema escolhido. Para estudos futuros recomenda-se a atualização monetária das demonstrações e a ampliação do estudo a outras cooperativas do mesmo ramo a fim de possibilitar uma base comparativa.
\end{abstract}

Palavras-chave: Análise Financeira, Demonstrações Contábeis, Cooperativas.

\begin{abstract}
The financial statements constitute an important instrument in aid of modern management, and its main objective is to generate information to support decisions to be taken. Organizations, individuals or corporations, seek to manage their resources to find out the production or financial costs and expenses. To this end, it is necessary an analysis of all the points where you can get a reduction of costs, to achieve an improvement in their revenues. Therefore, this case study which analyzed the financial economic situation of CAMSUL in the 2010-2014 period by calculating the liquidity ratios, profitability and debt and by vertical and horizontal analysis. The results presented by CAMSUL demonstrated that the cooperative is developing in recent years and expanding its activities in the business. During the preparation of the work, it was detected some limitations as lack of specific literature on the economic and financial analysis of cooperatives, which restricted the search by the lack of further information about the chosen topic. For future studies recommended to the restatement of the financial statements and the expansion of the study to other cooperatives in the same field to enable a comparative basis.
\end{abstract}

Keywords: Financial Analysis, Accounting statements, Cooperatives.

Recebido: 27/06/2016 Aceito: 02/11/2016

Marcia Helena dos Santos Bento ${ }^{1}$, Ester de Oliveira ${ }^{2}$, Lúcia Rejane da Rosa Gama Madruga ${ }^{3}$

1Universidade Federal de Santa Maria, Doutoranda do PPGA- marciabento@politecnico.ufsm.br- Colégio Politécnico da UFSM, Avenida Roraima, nº 1000, Campus UFSM, Prédio 70, Sala E-27

Bairro Camobi, Santa Maria, RS CEP 97105-900

Universidade Federal de Santa Maria, Tecnóloga em Gestão de Cooperativas- steh_@msn.com

3Universidade Federal do Rio Grande do Sul, Doutora em Agronegócios- nelguimachado@hotmail.com

\section{Introdução}




\section{A} s demonstrações financeiras constituem-se como um importante instrumento no auxílio da administração moderna, e tem como objetivo principal gerar informações para embasar as decisões a serem tomadas. Sendo assim, ela identifica, registra, mensura e possibilita a análise e predição dos eventos econômicos que alterem o patrimônio de uma entidade. Uma organização que não possua um sistema contábil eficaz na evidenciação das reais oscilações de sua riqueza, não estará apta a garantir sua continuidade (BRAGA, 2002).

Segundo Matarazzo (1998 apud Braga 2002) geralmente o diagnóstico de uma empresa começa com uma rigorosa Análise de Balanços para determinar quais os pontos críticos e permitir apresentar um esboço das prioridades para a solução de seus problemas.

As cooperativas agropecuárias se destacam por apresentar um grande número de associados e normalmente estes são os principais interessados em saber como seu investimento está sendo administrado. Segundo dados da Organização das Cooperativas Brasileiras - OCB (2015), aproximadamente 1,5 mil cooperativas são do ramo agropecuário com mais de 1 milhão de associados. Estas cooperativas são responsáveis por gerar 164 mil empregos diretos. Somente o ramo agropecuário é responsável por $48 \%$ da produção agropecuária nacional. O cooperativismo agropecuário é, portanto, um importante segmento para o desenvolvimento da região, no qual existe a predominância de atividades primárias, ou seja, a agricultura e pecuária.

As pessoas, jurídicas ou físicas, buscam gerenciar seus recursos, com o intuito de descobrir os custos e despesas, de produção ou financeiros. Para tanto, fazse necessário uma análise de todos os pontos onde pode se obter uma redução de custos, com a finalidade de conseguir uma melhora nas suas receitas.

Ching (2010) explica que as análises financeiras são de extrema importância para a cooperativa e também para os usuários destas demonstrações. Para os proprietários o interesse é na rentabilidade do negócio. Já os administradores podem determinar quais operações podem ser incrementadas ou reduzidas. Para os fornecedores a dúvida é aumentar ou diminuir o crédito. Os bancos preocupam-se com os empréstimos, enquanto o governo está atento aos tributos e assim por diante.

Nesse contexto, pretende-se analisar as demonstrações contábeis da Cooperativa Agropecuária Mista
Sul Riograndense - CAMSUL, por meio de Índices de Liquidez, Rentabilidade e Endividamento, e também por meio da Análise Vertical e Horizontal. A referida análise será baseada nos demonstrativos dos últimos cinco anos da cooperativa, utilizando-se de método comparativo anual.

A análise financeira de uma instituição é de grande importância para verificar o seu desempenho no mercado, independentemente de seu tamanho e de sua finalidade, onde há várias opções dentre os índices, que são instrumentos de análise e pode ser realizado por meio de instrumentos de análise de índices.

Têm-se os demonstrativos contábeis como fonte de informação, dos quais são extraídos os índices econômicos e financeiros, que mais tarde, serão alvos das interpretações para a tomada de decisão.

Diante destas considerações, faz-se o seguinte questionamento: Qual a situação econômica financeira da CAMSUL, de acordo com a análise das demonstrações contábeis dos últimos cinco anos?

Para responder a este questionamento, elaborou-se o seguinte objetivo geral: Identificar a situação econômica financeira da CAMSUL por meio da análise das demonstrações contábeis de 2010 a 2014.

Os objetivos específicos da pesquisa consistirão em: i. Realizar uma revisão bibliográfica acerca dos principais conceitos utilizados para a análise financeira das organizações; ii. Calcular os índices econômico-financeiros mais utilizados contabilmente; e iii. Analisar a situação econômica-financeira da cooperativa, com base nos índices já calculados.

O presente estudo de caso terá sua importância como fonte de informações oriundas das análises dos índices econômicos e financeiros, em que a cooperativa irá detectar sua atual situação. A indicação do desempenho econômico financeiro da cooperativa auxiliará a tomada de decisões em eventos futuros.

Braga (2002) enfatiza que tornar informações contábeis compreensíveis e úteis à cooperativa é papel da contabilidade. Por isso, é necessário adequá-las a necessidade de cada usuário. Então, busca-se na análise das demonstrações contábeis deixar essas informações mais elucidativas, de modo que fiquem compreensíveis a todos.

\section{Cooperativismo}


A cooperativa é denominada como uma associação autônoma de no mínimo vinte pessoas, unidas voluntariamente para atender necessidades econômicas, sociais e culturais comuns, por meio de uma empresa de propriedade coletiva e de controle democrático dos associados (MINISTÉRIO DA AGRICULTURA, 2012, p. 13).

Enquanto que para Bialoskorski (1998, apud Moura, 2008) define cooperativa como uma associação autônoma de pessoas que se unem voluntariamente para satisfazer aspirações e necessidades econômicas, sociais e culturais comuns, por meio de uma empresa de propriedade coletiva e gerida democraticamente. Nessas organizações, cada associado apresenta o direito de um único voto de cada investidor.

No Brasil, bem como em outros países, existe uma legislação específica para o cooperativismo. No caso brasileiro, o cooperativismo é regido pela Lei $\mathrm{n}^{\circ}$ 5.764 de 16 de dezembro de 1971 onde determina que "cooperativa é uma organização constituída para prestar auxílio socioeconômico aos seus associados que, voluntariamente a compõem e dela participam pela formação de uma organização democrática ativamente".

A Lei $n^{\circ}$ 5.764/71 disciplinou a criação de cooperativas, porém restringiu a autonomia dos associados, interferindo na criação, funcionamento e fiscalização do empreendimento cooperativo. A limitação foi superada pela Constituição de 1988, que proibiu a interferência do Estado nas associações, dando início a autogestão do cooperativismo (OCB, 2015).

Segundo DENACOOP (2006) foi no início do século XX que o cooperativismo começou a se delinear no Brasil, influenciado pela religiosidade e pelo pensamento político dos imigrantes. Os brasileiros registraram formalmente sua cooperativa pioneira em Minas Gerais, no ano de 1889, denominada como Sociedade Cooperativa Econômica dos Funcionários Públicos de Ouro Preto.

Porém a cooperativa mais antiga, ainda em funcionamento no Brasil, é do ramo de crédito. Em 1902, ela foi idealizada pelo padre jesuíta Theodor Amstad. A cooperativa era formada por colonos de origem alemã que habitavam Nova Petrópolis, no Rio Grande do Sul. A organização nasceu com o nome de Sociedade Cooperativa Caixa de Economia e Empréstimos de Nova Petrópolis e desde 1992 adota a denominação Sicredi Pioneira.
Os princípios do cooperativismo constituem um conjunto de normas que norteiam a constituição e o funcionamento das cooperativas.

Em setembro de 1995, em Manchester na Inglaterra, em um congresso realizado pela Aliança Cooperativa Internacional - ACI, foram estabelecidos os princípios cooperativistas e suas definições. São eles:

$1^{\circ}$. Adesão voluntária e livre: todas as pessoas que estejam aptas a utilizarem os serviços da cooperativa, e dispostas a assumirem responsabilidades como membros, são livres para ingressar na cooperativa, sem qualquer tipo de descriminação.

$2^{\circ}$. Gestão democrática: as cooperativas são organizações democráticas controladas por todos os seus cooperados que participam ativamente na formulação de políticas e na tomada de decisões. Os eleitos são responsáveis para com os demais sócios, e cada cooperado tem direito a um voto.

$3^{\circ}$. Participação econômica dos sócios: os membros contribuem equitativamente para o capital da cooperativa e controlam-no democraticamente. Se a cooperativa obtiver receitas maiores que as despesas estas também serão divididas equitativamente aos associados, proporcionalmente ao trabalho investido ou a utilização dos serviços da cooperativa. O restante das sobras deve ser decidido em assembleia, podendo ser reinvestido na cooperativa.

$4^{\circ}$. Autonomia e independência: As cooperativas são instituições autônomas, controladas por todos os seus membros, buscando atuar com a ajuda mútua e a gestão democrática.

$5^{\circ}$. Educação, formação e informação: as cooperativas promovem a educação, formação e informação dos seus cooperados, dirigente e colaboradores, buscando o desenvolvimento conjunto. Informando ao público em geral, principalmente aos jovens e aos formadores de opinião, as vantagens da cooperação.

$6^{\circ}$. Intercooperação: este princípio aborda a necessidade de haver a intercooperação entre cooperativas, as quais realizam troca de informação e experiências através de compras e/ou vendas em comum com a intenção de fortalecer o movimento cooperativo.

$7^{\circ}$. Interesse pela comunidade: As cooperativas trabalham para o desenvolvimento sustentável de suas comunidades, por meio de políticas aprovadas pelos membros (SILVA, ABRANTES E OLIVEIRA, 2012, p. 3).

Vale ressaltar que, em qualquer parte do mundo, independentemente dos regimes econômicos e políticos, as cooperativas seguem estes princípios na busca 
solidária de soluções para problemas comuns das pessoas que as integram.

\section{A Análise das Demonstrações Contábeis}

As demonstrações contábeis se referem aos relatórios que são produzidos pelos dados que se adquirem da contabilidade. Os inúmeros procedimentos contábeis que ocorrem a cada período são organizados e submetidos a evidenciar, por exemplo, a situação patrimonial da empresa em um dado momento, ou demonstrar quais foram as alterações ocorridas em seu patrimônio líquido de um ano para o outro, ou ainda desdobrar os passos que levaram a empresa a atingir um determinado resultado (SILVA, 2013).

No caso das cooperativas, Pereira (1995) explica que suas operações abrangem aspectos econômicos tal como verificados em qualquer outra empresa capitalista e também os aspectos sociais, entendido como sua principal finalidade, considerando o seu enquadramento no rol das empresas sem fins lucrativos.

Segundo Rios (2010) a análise das demonstrações contábeis é dividida em duas categorias. A primeira delas, a Análise Financeira, possibilita a interpretação da saúde financeira da empresa, seu grau de liquidez e capacidade de solvência. E a segunda, a Análise Econômica possibilita a interpretação das variações do patrimônio e da riqueza gerada por sua movimentação.

Segundo Zdanowicz (2013), as demonstrações financeiras têm como objetivo principal informar as situações econômicas financeiras e patrimoniais, de acordo com as mutações ocorridas no período extraídas de livros, registros e documentos da cooperativa.

Matarazzo (2010 apud Catapan, 2015) explica que a análise de balanços proporciona avaliações do patrimônio da empresa e das decisões tomadas, tanto em relação ao passado, como em relação ao futuro.

$\mathrm{Na}$ análise das demonstrações financeiras de uma empresa, maior ênfase é dada ao Balanço Patrimonial - BP e à Demonstração de Resultados do Exercícios DRE, uma vez que por meio dessas peças contábeis é evidenciada de forma objetiva a situação econômico financeira da empresa/cooperativa (CHING, 2010).

Segundo Cossermelli (2014), o balanço patrimonial é a demonstração contábil que nos fornece a posição patrimonial e financeira da empresa em uma data determinada, sendo considerada uma das mais importantes declarações da empresa.
Zdanowicz (2013) explica que o balanço patrimonial é a peça contábil que demonstra quantitativa e qualitativamente, em determinada data, o patrimônio da cooperativa. Os valores das contas que constam no balanço patrimonial refletem a situação do momento, pois no período seguinte, diversas contas poderão modificar seus saldos para mais ou para menos e algumas ficarem inalteradas.

Para Zdanowicz (2013), no Balanço Patrimonial as contas serão classificadas segundo os elementos do patrimônio que registram e agrupadas de modo a facilitar o conhecimento e a análise da situação financeira da cooperativa.

Quanto a sua composição, o Balanço Patrimonial é constituído pelo Ativo, Passivo e o Patrimônio Líquido. O Ativo compreende os bens, direitos e demais aplicações de recursos controlados pela entidade. O Passivo compreende as origens de recursos representados pelas obrigações com terceiros, resultantes de eventos ocorridos que exigirão ativos para a sua liquidação. Enquanto que o Patrimônio Líquido compreende os recursos próprios da Entidade, e seu valor é a diferença positiva entre o valor do Ativo e do Passivo (PORTAL DA CONTABILIDADE, 2015).

Segundo as Normas Brasileiras de Contabilidade, disponíveis no Portal da Contabilidade a denominação da Demonstração do Resultado do Exercício DRE é alterada para Demonstração de Sobras ou Perdas - DSP, ao tratar-se de sociedade cooperativa. A DSP deve evidenciar, separadamente, a composição do resultado de determinado período, considerando os ingressos diminuídos dos dispêndios do ato cooperativo, e das receitas, custos e despesas do ato nãocooperativo, demonstrados segregadamente por produtos, serviços e atividades desenvolvidas pela Entidade Cooperativa (PORTAL DA CONTABILIDADE, 2015).

A DSP relaciona as operações realizadas pela cooperativa durante o período, informando as sobras ou perdas líquidas. Essa demonstração evidencia a composição do resultado gerado pelas operações da cooperativa de acordo com o princípio contábil de competência (ZDANOWICZ, 2013).

Com o intuito de facilitar o desenvolvimento dos processos de análise, é necessário que se mantenha um padrão nas demonstrações contábeis. Segundo Moura (2009) a elaboração de demonstrações padronizadas para fins de análise é importante, pois as demonstrações elaboradas pelas Entidades, publicadas ou não, contém um número excessivo de contas. Es- 
sas contas, se forem analisadas da forma em que se encontram, poderão causar embaraços ao analista.

O presente estudo de caso baseou-se no modelo de padronização proposto por Moura (2009). Vale ressaltar a seguir algumas contas que foram agrupadas seguindo o modelo.

Na padronização não constam, por exemplo, contas retificadoras. As contas do Ativo Circulante e do Passivo Circulante foram reclassificadas em Operacional e Financeiro. Para facilitar a coleta de dados, pode-se englobar os subgrupos Investimentos, Imobilizado e Intangível do Ativo Não-Circulante em um só, que poderá receber a denominação de Ativo Fixo ou Ativo Permanente (MOURA, 2009).

A finalidade da análise horizontal é apontar a variação de itens das demonstrações contábeis através de períodos, a fim de caracterizar tendências (RIOS, 2010).

Segundo Ching (2010) a análise horizontal permite examinar a evolução da variação das contas do Balanço Patrimonial e da Demonstração de Resultados do Exercício de um período para o outro, tomando o período anterior como base. Essa técnica mostra a evolução de cada conta ou grupo de contas ao longo dos períodos.

A análise vertical possui uma técnica bastante simples para cálculo. Este tipo de análise é importante para avaliar a estrutura de composição de itens e sua evolução no tempo (RIOS, 2010).

Ching (2010) explica que a análise vertical do Balanço Patrimonial permite visualizar, do lado do passivo, a parcela de participação de cada fonte de recursos, enquanto na Demonstração de Resultados mostra as variações de um ano para o outro.

A análise de índices ou quocientes relaciona itens e grupos de itens do balanço patrimonial e da demonstração de resultados, no caso das cooperativas, o demonstrativo de sobras ou perdas. Estes índices analisam a rotatividade da empresa/cooperativa, ou seja, sua capacidade de liquidar suas dívidas.

Segundo Ching (2010), o uso de índices reveste-se de grande utilidade para a análise de crédito e de tendências. Os índices facilitam o trabalho de análise, pois a observação de certos quocientes é mais relevante que o exame de valores por si só. Os principais quocientes são: Índice de Liquidez Corrente, Índice de Liquidez Seca e o Índice de Liquidez Imediata, sendo estes, alvo de análise no presente artigo.

O Índice de Liquidez Corrente indica se a quantidade de recursos que a empresa tem no ativo circulan- te é suficiente para pagar as dívidas constantes no passivo circulante. Este índice permite conhecer como está a liquidez da empresa em curto prazo (PORTAL DA EDUCAÇÃO, 2015).

Para calcular o Índice de Liquidez Corrente foi dividido o Ativo Circulante pelo Passivo Circulante, conforme fórmula 1. Este índice determina quanto a empresa dispõe de direitos realizáveis a curto prazo para cada $\mathrm{R} \$ 1,00$ de dívidas de curto prazo.

$$
\begin{gathered}
\text { Liquidez Corrente }=\frac{\text { Ativo Circulante }}{\text { Passivo Circulante }} \\
\text { Pal }
\end{gathered}
$$

O Índice de Liquidez Seca propicia uma análise mais conservadora e realista da situação de liquidez da empresa em determinado momento, pois elimina o risco associado a incerteza da venda dos estoques (CHING, 2010). A exclusão dos estoques é necessária para verificar se a empresa depende das vendas para liquidar seus compromissos.

Para cálculo do Índice de Liquidez Seca foram diminuídos do Ativo Circulante os Estoques, dividido pelo Passivo Circulante, conforme fórmula 2. Em poucas palavras, este índice determina quanto de dívidas de curto prazo podem ser saldadas utilizando o ativo circulante e desprezando os estoques.

$$
\begin{gathered}
\text { Liquidez Seca }=\underline{\text { Ativo Circulante }- \text { Estoques }} \\
\text { Passivo Circulante }
\end{gathered}
$$

O Índice de Liquidez Imediata mostra o montante de dinheiro de que a empresa/cooperativa dispõe no ato, isto é, sua disponibilidade para honrar as dívidas de curto prazo, ou seja, todo o seu Passivo Circulante.

Esse indicador examina a liquidez da empresa com o máximo de rigor, pois revela se ela tem caixa de imediato para quitar qualquer compromisso de curto prazo (Ching, 2010). Para cálculo do Índice de Liquidez Imediata foram divididas as Disponibilidades pelo Passivo Circulante, conforme fórmula 3.

$$
\begin{gathered}
\text { Liquidez Imediata }=\text { Disponibilidades } \\
\text { Passivo Circulante }
\end{gathered}
$$

Ressalta-se que segundo Moura (2009) para fins de análise, a conta caixa é considerada em um sentido amplo, ou seja, compõe o grupo Disponibilidades as contas designativas de caixa, de contas bancárias e de aplicações de liquidez imediata.

Este índice, como diz o nome, é responsável por revelar o grau de endividamento da cooperativa/empresa. Carvalho (2003) explica que "a análise deste indicador por diversos exercícios mostra a polí-

RGC, Santa Maria, v.3, n.6, Págs. 15-30, jul./dez. 2016 
tica de obtenção de recursos da empresa, ou seja, se a empresa vem financiando o seu Ativo com recursos próprios ou de terceiros e em quais proporções".

Segundo Gitman (1997), quanto mais recursos de terceiros a empresa utiliza em relação ao seu ativo, mais será a sua alavancagem financeira, termo utilizado para descrever a ampliação do risco e do retorno ocasionada pelo uso de financiamento a custos fixos, como dívida e ações preferenciais. Em outras palavras, quanto maior o endividamento a custos fixos, ou alavancagem financeira, de uma empresa, maior serão o seu risco e retorno esperados.

No índice de endividamento foram analisados o Índice de Participação de Capital de Terceiros, o Grau de Endividamento e a Composição do Endividamento.

O Índice de Participação de Capital de Terceiros (PCT) indica o percentual de Capital de Terceiros em relação ao Patrimônio Líquido, retratando a dependência da empresa em relação aos recursos externos (CARVALHO, 2003).

Para o cálculo do PCT foi feita a soma do Passivo Circulante e do Passivo Não Circulante divididos pelo total do Ativo, conforme fórmula 4.

$$
\text { PCT }=\frac{\text { Passivo Circulante }+ \text { Passivo Não Circulante }}{\text { Ativo }}
$$

O Índice do Grau de Endividamento, para Freitas (2015), relaciona duas grandes fontes de recursos da empresa/cooperativa: as fontes de capital próprio e as fontes de capital de terceiros. Este índice é um indicador de risco ou de dependência de terceiros por parte da empresa.

Para o cálculo do Grau de Endividamento foram somados Passivo Circulante e Passivo Não Circulante divididos pelo Patrimônio Líquido (fórmula 5).

$$
\mathrm{GE}=\frac{\text { Passivo Circulante }+ \text { Passivo Não Circulante }}{\text { Patrimônio Líquido }}
$$

A Composição do Endividamento segundo Carvalho (2003), indica quanto da dívida total da empresa deverá ser paga a curto prazo, ou seja, as obrigações a curto prazo comparadas com as obrigações totais.

Para o cálculo da Composição do Endividamento, o Passivo Circulante foi dividido pela soma do Passivo Circulante e do Passivo Não Circulante (fórmula $6)$.

$$
\mathrm{CE}=\frac{\text { Passivo Circulante }}{\text { Passivo Circulante }+ \text { Passivo Não Circulante (6) }}
$$

Para Silva (2003, p.3) "os índices de rentabilidade procuram evidenciar qual foi a rentabilidade dos capitais investidos, ou seja, o resultado das operações realizadas por uma organização". Este índice serve para medir a capacidade econômica da empresa / cooperativa.

No índice de rentabilidade são analisados o Retorno Sobre o Ativo - ROA, Retorno Sobre Investimentos - ROI e o Retorno Sobre o Patrimônio Líquido ROE.

Para Vieira (2011, p. 4) "o ROA significa a taxa de retorno gerado pelas aplicações realizadas por uma empresa em seus ativos". Este índice indica o retorno gerado por cada $\mathrm{R} \$ 1,00$ investido pela empresa/cooperativa.

Para cálculo do ROA dividide-se o Lucro Líquido (ano base) pela média do Ativo Circulante - AC (soma ano anterior e ano base divididos por dois), ou seja, para calcular o ano de 2011, foi soma-se o ativo circulante de 2010 com o ativo circulante de 2011 e divide por dois (fórmula 7).

$$
\begin{aligned}
& \mathrm{ROA}=\frac{\text { Lucro Líquido }}{\mathrm{AC}(\text { ano anterior })+\mathrm{AC}(\text { ano base }) / 2}
\end{aligned}
$$

Para Assaf Neto (2009 apud Vieira, 2011) o Retorno Sobre Investimentos (ROI) é uma alternativa ao uso da ROA para avaliar o retorno produzido pelo total dos recursos aplicados por acionistas e credores nos negócios. Em outras palavras a ROI é a relação entre o dinheiro ganho ou perdido através de um investimento, e o montante de dinheiro investido.

Para cálculo do ROI divide-se a sobra do exercício (ano base) pela média do ativo operacional - AO (soma do ano anterior e ano base dividido por dois), conforme fórmula 8 .

$$
\mathrm{ROI}=\frac{\text { Sobra do Exercício }}{\mathrm{AO}(\text { ano anterior })+\mathrm{AO}(\text { ano base }) / 2}
$$

Assaf Neto (2009 apud Vieira, 2011, p. 5) explica que o Retorno Sobre o Patrimônio Líquido - ROE "trata-se da mensuração do retorno que a empresa tem dos recursos aplicados por seus proprietários" (no caso das cooperativas, associados), ou seja, para cada $\mathrm{R} \$ 1,00$ de recursos próprios (Patrimônio Líquido) investido na empresa, quanto os cooperados obtém de retorno. Para o cálculo do ROE foi dividido a sobra líquida (ano base) pela média do Patrimônio Líquido - PL (soma do ano anterior e ano base divididos por 2), conforme fórmula 9. 
$\mathrm{ROE}=$

Sobra Líquida

PL (ano anterior) + PL (ano base) / 2

Vale ressaltar que o cálculo dos índices de rentabilidade do ano de 2010 não foram possíveis, pois, conforme pode ser visto nas fórmulas, é necessário um ano anterior e um ano base. Portanto, só se obteve resultados a partir do ano de 2011. Esta foi uma exceção para o índice de rentabilidade.

\section{Metodologia}

Para Kerlinger (1980), define-se delineamento da pesquisa como o plano e a estrutura da investigação, concebidos de forma a obtermos respostas para as perguntas da pesquisa.

Segundo Gil (2012), o estudo de caso é uma modalidade de pesquisa amplamente utilizada. Consiste no estudo profundo e exaustivo de um ou poucos objetos, de maneira que permita seu amplo e detalhado conhecimento. Seus resultados, de modo geral, são apresentados em aberto, ou seja, na condição de hipóteses, não de conclusões.

Quanto aos fins da pesquisa, se caracteriza como descritiva, pois expõe características de determinada população ou determinado fenômeno. A pesquisa descritiva não tem compromisso de explicar fenômenos que descreve, embora sirva de base para tal explicação (VERGARA, 2014a).

Quanto aos meios de investigação, o presente estudo pode ser classificado como uma pesquisa de campo. Vergara (2014b) explica que a pesquisa de campo é a investigação empírica realizada no local onde ocorre ou ocorreu um fenômeno ou que dispõe de elementos para explica-lo. Pode incluir entrevistas, aplicação de questionários, testes e observação participante ou não.

Classifica-se também como bibliográfica, pois é elaborada com base em material já publicado e é documental, pois é realizada com base nos documentos conservados no interior de órgãos públicos e privados ou com pessoas (VERGARA, 2014c).

Gil (2012) explica que a pesquisa documental apresenta muitos pontos de semelhança com a pesquisa bibliográfica, posto que nas duas modalidades utilizam-se dados já existentes. A principal diferença está na natureza das fontes. A pesquisa bibliográfica fundamenta-se em material elaborado por autores com o propósito especifico de ser lido por públicos específicos. Já a pesquisa documental vale-se de toda sorte de documentos, elaborados com finalida- des diversas, tais como assentamento, autorização, comunicação (GIL, 2012, p. 30).

O objeto do estudo, a Cooperativa Agrícola Mista Sul Riograndense - CAMSUL, foi fundada em 2002, em Santa Maria, RS, e é uma cooperativa do ramo agropecuário que se baseia na colaboração recíproca de seus associados que tem em comum o desenvolvimento e a prática do uso de uma agricultura tecnificada (CAMSUL, 2015a).

Carlesso (2006 p.43) determina os principais objetivos da cooperativa. São eles:

1- Por meio da colaboração recíproca entre seus associados e com o uso de recursos técnicos e de maquinário apropriado e moderno, ambicionar realizar uma agricultura altamente tecnificada; tendo como consequência uma melhora em todos os sentidos na vida dos cooperados;

2- Por intermédio do estimulo progressivo, contribuir para que seus cooperados consigam desenvolver satisfatoriamente suas atividades, inclusive as atividades econômicas de caráter comum;

3- Os artigos necessários a consecução da atividade a que se propõe a sociedade assim composta, e que traz um incremento na lavoura dos associados, são sempre adquiridos em comum;

4- Serão fornecidos também todos os serviços de ordem geral e afins, que visam a redução de custos e aumento da produtividade;

5- Os produtos produzidos pelos seus associados são recebidos, estocados, secos e comercializados pela cooperativa. (CARLESSO, 2006, p. 43)

Sua denominação é dada pelos seguintes aspectos: Agrícola, pois está diretamente relacionada a agricultura e/ou pecuária. Mista por combinar atividades de produção e consumo, ou seja, ela adquire os grãos produzidos pelos associados e negocia no mercado, o que elimina os custos intermediários e agrega valor ao produto do associado, além de adquirir os produtos necessários para o cultivo da lavoura e repassar aos associados. E por fim, Sul Riograndense por sua localização, que se encontra na metade sul do RS (CAMSUL, 2015c).

Atualmente, a cooperativa conta com mais de oito colaboradores, além dos membros do conselho administrativo e fiscal. Também proporciona assessoria agronômica, constituída de agrônomos e técnicos agrícolas e mais de mil e duzentos associados em seu quadro. Sua missão é oportunizar a integração entre os cooperados, a cooperativa e o mercado, sempre buscando inovação e novas tecnologias, a fim de 
estimular o aumento da produtividade, fazendo com que haja um aumento da rentabilidade tanto para o cooperado quanto para a cooperativa, que reverterá em benefícios sociais e sobras aos cooperados (CAMSUL, 2015d).

Por ser considerada uma cooperativa referência para a região e pela sua localidade, foi escolhida pela autora para ser o objeto de estudo de pesquisa a fim de levantar dados referentes a sua contabilidade, bem como analisá-los através das demonstrações contábeis, com foco na análise vertical e horizontal e nos índices de liquidez, rentabilidade e endividamento.

A coleta de dados foi realizada na sede da cooperativa, com base na obtenção dos balanços patrimoniais e do demonstrativo do resultado do exercício dos últimos cinco anos, de 2010 a 2014.

Os dados foram obtidos por meio de uma fonte primária, o que elimina o risco dos dados terem sido manipulados por terceiros ou fontes secundárias.

Os demais procedimentos apresentados foram baseados em pesquisa bibliográfica e artigos com dados pertinentes ao tema e problema. Além disso, foram realizadas visitas a cooperativa visando a observação do local e a obtenção de informações relevantes ao presente estudo.

\section{Análise dos Resultados}

Os índices de liquidez são responsáveis por avaliar a capacidade de pagamento da empresa/cooperativa. Quanto a análise do índice de liquidez corrente pôdese observar um aumento significativo de 2010 a 2011 de 1,7 , porém se constatou uma constante queda nos anos posteriores, chegando a 1,4 em 2014.

Apesar da variação, pode se dizer que a cooperativa tem uma boa capacidade de pagamento a curto prazo, pois durante os cinco anos a cooperativa manteve o índice de liquidez corrente igual ou acima de 1, o que pode se considerar uma situação ideal.

A análise do índice de liquidez seca é responsável por indicar quanto a empresa/cooperativa possui em disponibilidades, excluindo os estoques, ou seja, dinheiro, depósitos bancários e aplicações financeiras. No caso da CAMSUL pôde-se identificar que o índice de liquidez seca se manteve acima ou igual a 1 no decorrer dos cinco anos, ou seja, que a cooperativa possui condições de liquidar suas dívidas de curto prazo sem contar com seus estoques.
O índice de liquidez imediata, como diz o nome, é responsável por avaliar quanto a empresa/cooperativa teria disponível de imediato para pagar suas obrigações.

Souza (2003) explica que, embora no geral os indicadores de liquidez sejam avaliados em quanto maior melhor, com relação ao índice de liquidez imediata isso não é conveniente uma vez que, um índice elevado pode significar ociosidade de recursos.

Portanto, no caso da CAMSUL, foi observado que os índices de liquidez imediata dos cinco anos se mantiveram abaixo de 1 , ou seja, a cooperativa não seria capaz de quitar suas dívidas no curto prazo com seu caixa e equivalentes. Porém, este não pode ser considerado um fator ruim para a cooperativa, pois significa que seus recursos não estão ociosos, ou seja, estão investidos em aplicações financeiras de longo prazo, etc.

Estes indicadores podem ser observados no gráfico a seguir.

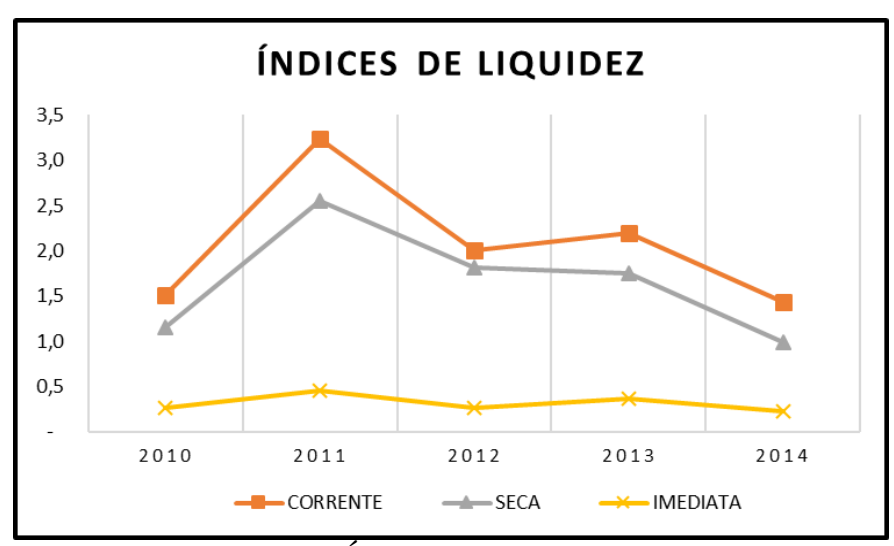

Gráfico 1 - Análise dos Índices de Liquidez

Em geral, pode-se dizer que a CAMSUL possui uma boa capacidade financeira para fazer frente ao cumprimento de suas obrigações.

A análise dos Índices de Rentabilidade é responsável por medir o quanto uma empresa/cooperativa pode estar sendo rentável ou não, por meio dos capitais investidos. Para análise, o seu conceito é quanto maior melhor.

$\mathrm{Na}$ análise do Retorno Sobre o Ativo - ROA, pode-se observar uma pequena variação de $0,01 \mathrm{em}$ relação a 2011 e 2014. Isto significa que para cada $\mathrm{R} \$$ 1,00 de ativo investido, a cooperativa gerou $\mathrm{R} \$ 0,01$ de retorno/sobras. Este índice pode ser considerado baixo, porém, em se tratando de cooperativas, não se pode dizer que seja um índice ruim, visto que cooperativas não visam ao lucro e sim satisfazer as aspirações e necessidades dos cooperados. 
Em relação ao Retorno Sobre o Investimento ROI este estabelece a competência dada pela administração ao Ativo Operacional utilizado. Quanto maior o ROI maior a rentabilidade da empresa/cooperativa. Este índice variou 0,01 para mais e para menos no decorrer dos quatro anos, sendo 2011 e 2013 os que variaram para mais e 2012 e 2014 os que variaram para menos, respectivamente. Isto significa que para cada R\$ 1,00 investido em aplicações, as mesmas renderam $\mathrm{R} \$ 0,01$.

Por mais baixo que tenha sido o rendimento, podemos considerar estes como sendo bons índices, pois se mantiveram acima de zero durante os quatro anos. Tanto o ROA como o ROI são importantes, pois permitem comparar empresas/cooperativas de quaisquer tamanhos.

Foi constatado na análise do Retorno Sobre o Patrimônio Líquido - ROE um significativo aumento no decorrer dos quatro anos, diferente da análise do ROA e do ROI. De 2011 a 2012 o aumento foi de 0,01 enquanto que de 2013 a 2014 o aumento foi de 0,03, ou seja, de 2011 a 2014 a variação foi de 0,07. Isto significa que para cada $\mathrm{R} \$ 100,00$ de recursos próprios investidos na cooperativa, o retorno/sobra para os associados de 2011 a 2014 foi de R\$ 0,07.

Novamente a cooperativa apresentou índices positivos durante o período analisado. Este é um excelente indicador para a cooperativa, visto que ela está cumprindo com o seu papel para com o associado.

Estes indicadores podem ficar mais claros visualizando o gráfico abaixo.

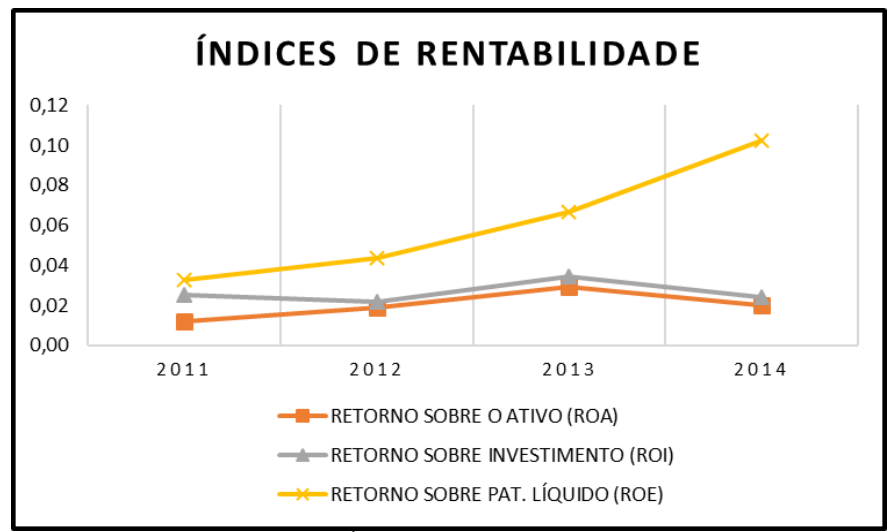

Gráfico 2 - Análise dos Índices de Rentabilidade

Os Índices de Endividamento relacionam a posição do capital próprio (Patrimônio Líquido) com a posição do capital de terceiros (empréstimos).

O Índice de Participação de Capital de Terceiros mostra o quanto do Ativo Total está sendo financiado com recursos de terceiros. Quanto maior for este quociente, mais endividada estará a cooperativa.

Este índice apresentou uma variação de 0,62 em 2010 para 0,66 em 2014. Isto significa que para cada $\mathrm{R} \$ 100,00$ financiados $\mathrm{R} \$ 62,00$ está sendo financiado com recursos de terceiros.

O Grau de Endividamento representa quanto a cooperativa tomou de capital de terceiros para cada $\mathrm{R} \$$ 100,00 de capital próprio, ou seja, índices maiores que 1 podem revelar dependência em relação ao capital de terceiros.

$\mathrm{Na}$ análise do Grau de Endividamento os índices diminuíram de 2010 a 2013, passando de 1,66 em 2010 para 1,52 em 2013. Porém, houve um significativo aumento de 2013 a 2014 de 1,52 para 19,78, ou seja, em 2014 a cooperativa revelou significativa dependência ao capital de terceiros. Este índice aponta que a cooperativa deve mais para terceiros do que para seus cooperados.

A Composição do Endividamento indica qual o percentual de obrigações a curto prazo com relação à dívida total. É por meio deste índice que a cooperativa vai saber se a maior parte de suas dívidas é de curto ou longo prazo.

$\mathrm{Na}$ análise da Composição do Endividamento foi constatada uma queda de $0,48 \%$ em relação a 2010 e 2011. Em 2013 e 2014 os índices se mantiveram estáveis em 0,67, porém em 2014 houve um aumento de 0,28 finalizando o ano de 2014 em 0,95. Estes índices indicam que a cooperativa possui a maior parte de suas dívidas concentradas no curto prazo, o que não resulta em um ambiente ideal.

Os índices de endividamento podem ser observados no gráfico abaixo.

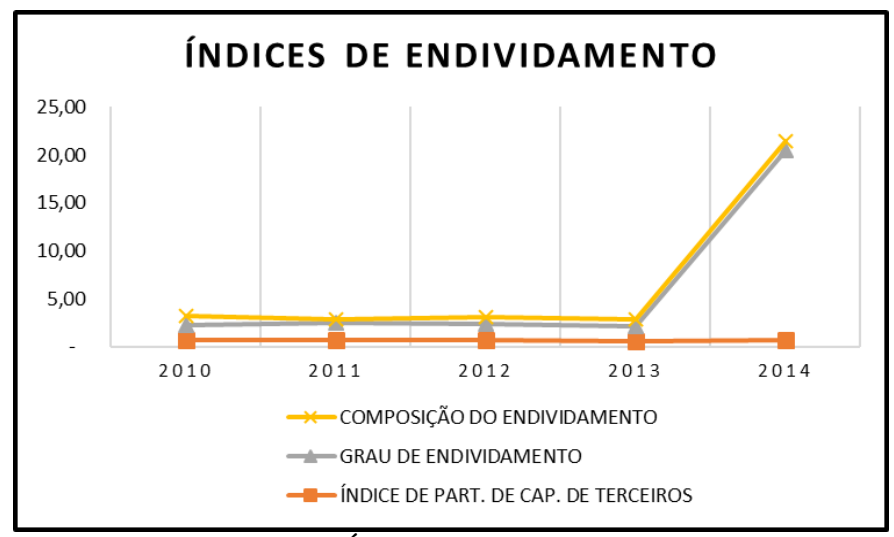

Gráfico 3 - Análise dos Índices de Endividamento

Em geral, pode-se dizer que a cooperativa possui maior parte de suas dívidas concentradas em curto 
prazo e que grande parte de seus financiamentos estão sendo com terceiros.

$\mathrm{Na}$ análise vertical foi verificado, dentro do Ativo Circulante, analisando o ano de 2010, um total de $8,76 \%$ de ativos financeiros e $73,95 \%$ de ativos operacionais. Em 2014 estes índices passaram para $500,26 \%$ de ativo financeiro e $305,74 \%$ de ativo operacional. No Ativo Financeiro a conta que mais se destacou foi os Cheques a Receber, com uma variação de 2,06\% em 2010 e 13,47\% em 2014. A conta Aplicações Financeiras apresentou uma queda de $4,89 \%$ de 2010 a 2014.

No Ativo Operacional a conta Clientes apresentou uma variação surpreendente. Em 2010 a análise vertical era de 2,06\% enquanto que em 2014 passou para $1.952,43 \%$. Sem dúvidas esta conta foi a que mais obteve destaque na análise vertical. A respeito dos Estoques, os mesmos aumentaram de 19,38\% em 2010 para 27,65\% em 2014.

No Ativo Não Circulante, o Imobilizado apresentou uma queda de $6,96 \%$. Em 2010 estava representado por $16,39 \%$ passando para $9,43 \%$ em 2014. Podese observar isto no gráfico a seguir.

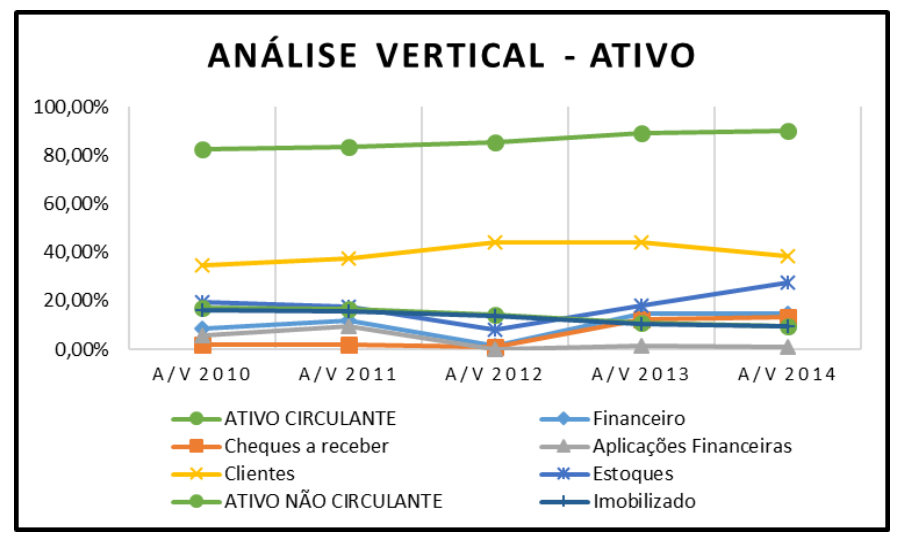

Gráfico 4 - Análise vertical do ativo

$\mathrm{Na}$ análise vertical do Passivo Circulante foram verificados em 2010 14,72\% de passivo financeiro e $40,22 \%$ de passivo operacional. Estes apresentaram significativo aumento, passando para $317,92 \%$ de passivo financeiro e $351,29 \%$ de passivo operacional em 2014. No passivo operacional a conta que mais se destacou foi a dos Fornecedores. Em 2010 apresentava uma variação de $22,01 \%$ passando para $33,10 \%$ em 2014.

No Passivo Não Circulante o Patrimônio Líquido apresentou uma significativa queda, passando de 37,65\% em 2010 para 3,34\% em 2014. As Sobras Acumuladas aumentaram durante o período analisa- do. O gráfico a seguir mostra a variação da Análise Vertical do Passivo.

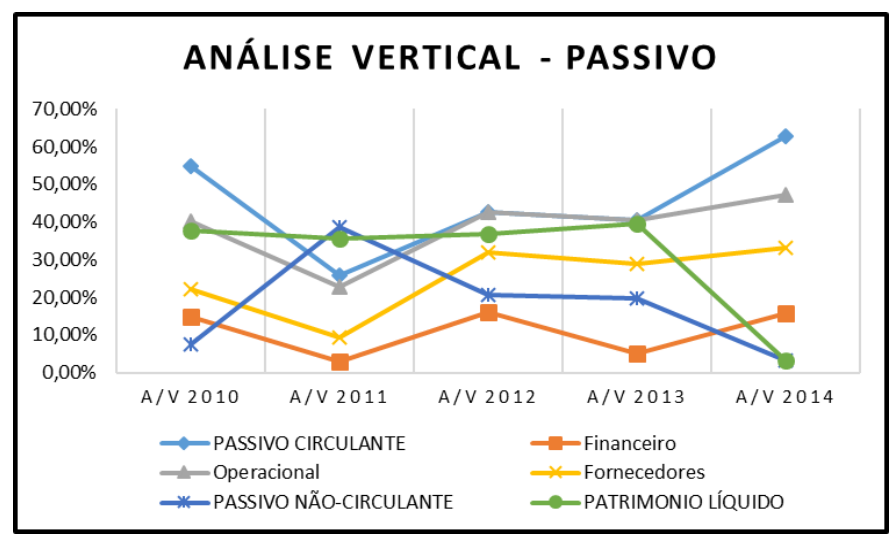

Gráfico 5 - Análise vertical do passivo

Na Análise Vertical do DSP, a conta Ingressos Líquidos, foi tomada como base representando $100 \%$. No Custo dos Ingressos a variação foi de 2,07\% em relação ao período de 2010 a 2014. Em relação as Sobras Brutas, as mesmas diminuíram de $17,59 \%$ em 2010 para $15,52 \%$ em 2014. Para maior clareza e visualização, a análise vertical do DSP foi dividida em dois gráficos. $\mathrm{O}$ gráfico a seguir representa os índices das contas Ingressos Líquidos, Custo dos Ingressos e as Sobras Brutas.

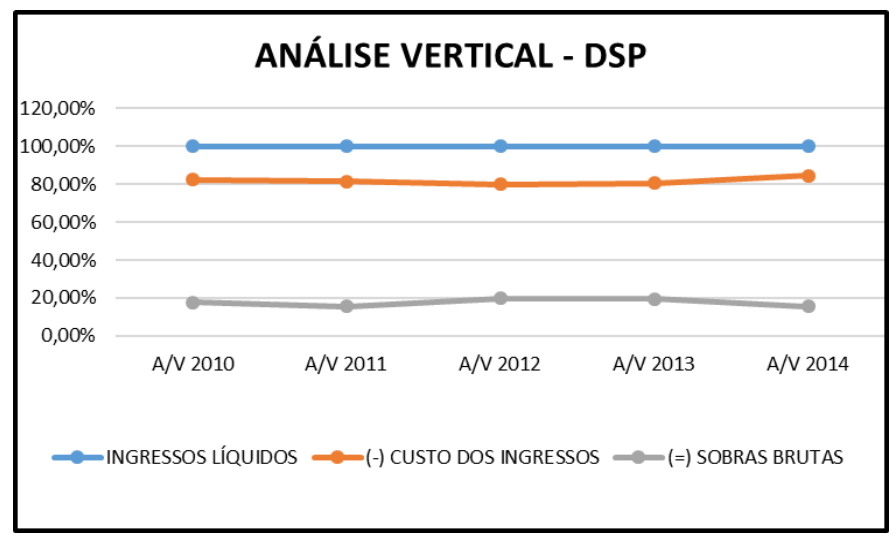

Gráfico 6 - Análise Vertical do DSP

A conta Ingressos Operacionais também apresentou uma queda 1,33\% de 2010 a 2014. As Despesas Administrativas se destacam mais que as Despesas com Vendas, porém as duas apresentaram uma diminuição no período.

O Resultado Financeiro apresentou uma pequena variação de 1,97\% durante o período analisado, enquanto que as Sobras Operacionais variaram de 9,92\% em 2010 para 9,24\% em 2014. O Fundo de Reserva apresentou um pequeno aumento de 0,03\% no período analisado, enquanto que o FATES diminuiu de 2,33\% em 2010 para 1,54\% em 2014. As Sobras Líquidas do Exercício apresentaram constante aumen- 
to no período. Em 2010 eram de 6,20\% passando para 6,43\% em 2014.

Estes indicadores podem ser visualizados no segundo gráfico da Análise Vertical do DSP.

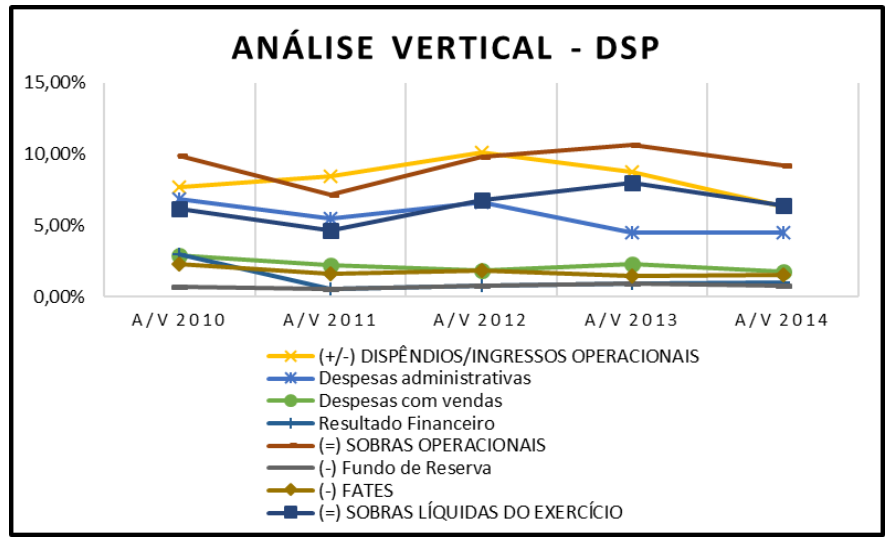

Gráfico 7 - Análise vertical do DSP

$\mathrm{Na}$ Análise Horizontal ficou definido como 2010 sendo o ano base para cálculo, tanto para o Balanço Patrimonial quanto para o DSP, ou seja, o cálculo da análise horizontal foi feito sempre comparando o ano posterior com o ano base.

Fazendo uma comparação entre o Ativo Circulante e o Ativo Não Circulante, quem obteve maior variação positiva foi o Ativo Circulante. $\mathrm{O}$ circulante apresentou uma variação de 326,35\% em 2014 enquanto que o não circulante variou 168,56\%. Dentro do Ativo Circulante a conta Ativo Financeiro se destacou mais que a conta Ativo Operacional. Em 2010 estas duas contas representavam 100\% (ano base) passando $500,26 \%$ (financeiro) e 305,74\% (operacional) em 2014, respectivamente.

Dentro do Ativo Financeiro a conta que mais se evidenciou foi a dos Cheques a Receber apresentando uma impressionante variação de $1.952,43 \%$ no ano de 2014. Este aumento deu-se devido a diminuição da conta Aplicações Financeiras, que diminuiu de 100\%, em 2010, para 43,04\% em 2014. Vale ressaltar que grande parte dos produtos são pagos na "safra", por meio de recebimento de cheques. Isto justifica o súbito aumento da conta Cheques a Receber. A conta Caixa também apresentou aumento durante o período analisado e chegou ao seu ápice em 2013 com $304,75 \%$, fechando o período com queda para $233,13 \%$.

Ainda no Ativo Circulante, analisando o Ativo Operacional, a conta que mais se destacou foram os Estoques, no qual apresentou uma variação de $426,77 \%$ em 2014. A conta Clientes apresentou constante aumento durante o período analisado com uma variação de 332,78\% em 2014. Já no Ativo Não Circulante, o Ativo Fixo variou 168,56\% durante o período, enquanto que o Imobilizado apresentou um aumento de $172,17 \%$ em 2014. O quadro a seguir demonstra a Análise Horizontal do Ativo.

\begin{tabular}{|c|c|c|c|c|c|}
\hline & A/H 2010 & A/H 2011 & A/H 2012 & AVH 2013 & A/H 2014 \\
\hline ATIVO & $100 \%$ & $121,00 \%$ & $149,47 \%$ & $195,14 \%$ & $299,07 \%$ \\
\hline ATIVO CIRCULANTE & $100 \%$ & $122,12 \%$ & $154,62 \%$ & $210,47 \%$ & $326,35 \%$ \\
\hline Financeiro & $100 \%$ & $164,01 \%$ & $25,57 \%$ & $331,11 \%$ & $500,26 \%$ \\
\hline Caixa & $100 \%$ & $282,51 \%$ & $209,50 \%$ & $304,75 \%$ & $233,13 \%$ \\
\hline Cheques a receber & $100 \%$ & $114,74 \%$ & $82,30 \%$ & $1169,59 \%$ & $1952,43 \%$ \\
\hline Aplicações Financeiras & $100 \%$ & $205,49 \%$ & $0,00 \%$ & $55,95 \%$ & $43,04 \%$ \\
\hline Operacional & $100 \%$ & $117,16 \%$ & $149,67 \%$ & $196,17 \%$ & $305,74 \%$ \\
\hline Clientes & $100 \%$ & $131,64 \%$ & $190,38 \%$ & $248,51 \%$ & $332,78 \%$ \\
\hline Estoques & $100 \%$ & $110,47 \%$ & $61,11 \%$ & $184,12 \%$ & $426,77 \%$ \\
\hline Despesas do exercício seguinte & $100 \%$ & $99,89 \%$ & $66,45 \%$ & $61,79 \%$ & $68,14 \%$ \\
\hline ATIVO NÃO CIRCULANTE & $100 \%$ & $115,62 \%$ & $124,82 \%$ & $121,82 \%$ & $168,56 \%$ \\
\hline Ativo Fixo & $100 \%$ & $115,62 \%$ & $124,82 \%$ & $121,82 \%$ & $168,56 \%$ \\
\hline Imobilizado & $100 \%$ & $116,46 \%$ & $126,04 \%$ & $122,85 \%$ & $172,17 \%$ \\
\hline
\end{tabular}

Quadro 1 - Análise horizontal do ativo

$\mathrm{Na}$ análise horizontal do Passivo, fazendo uma comparação entre Passivo Circulante e Passivo Não Circulante, o circulante apresentou uma variação maior de $342,35 \%$, enquanto que o Não Circulante variou 126,57\%. Com relação ao Passivo Financeiro e ao Passivo Operacional, o segundo obteve maior variação. A conta Adiantamentos teve um aumento signi- ficativo no período. Em 2013, a análise horizontal era de $87,66 \%$ passando para surpreendentes $637,69 \%$ em 2014. Esta conta foi a que mais se destacou na análise horizontal do passivo. Ainda no Passivo Operacional a conta Fornecedores também apresentou aumento no período, variando em 449,77\% em 2014. 
No Passivo Financeiro a única conta analisada foi a de Empréstimos e Financiamentos, que apresentou aumento, fechando o ano de 2014 com variação de $317,92 \%$. No Passivo Não Circulante as Obrigações de Longo Prazo diminuíram no decorrer do período analisado, passando dos 630,86\% em 2011 para 126,57\% em 2014. Uma significativa queda.

Analisando o Patrimônio Líquido da cooperativa, constatou-se uma importante diminuição de 2013 a
2014. Analisando os anos anteriores, o patrimônio vinha apresentando aumento, no entanto a diminuição ocorreu no ano de 2013 para 2014, passando de $205,77 \%$ para $26,51 \%$, respectivamente. As Sobras Acumuladas apresentaram aumento no período, variando em 386,27\% em 2014. O quadro a seguir apresenta a análise horizontal do Passivo.

\begin{tabular}{|c|c|c|c|c|c|}
\hline & AH 2010 & AH 2011 & A/H 2012 & A/H 2013 & A/H 2014 \\
\hline PASSIVO CIRCULANTE & $100 \%$ & $56,76 \%$ & $116,02 \%$ & $143,93 \%$ & $342,35 \%$ \\
\hline Financeiro & $100 \%$ & $24,94 \%$ & $161,62 \%$ & $65,67 \%$ & $317,92 \%$ \\
\hline Empréstimos e financiamentos & $100 \%$ & $24,94 \%$ & $161,62 \%$ & $65,67 \%$ & $317,92 \%$ \\
\hline Operacional & $100 \%$ & $68,41 \%$ & $158,48 \%$ & $196,59 \%$ & $351,29 \%$ \\
\hline Fornecedores & $100 \%$ & $51,35 \%$ & $217,85 \%$ & $255,93 \%$ & $449,77 \%$ \\
\hline Adiantamentos & $100 \%$ & $104,50 \%$ & $72,25 \%$ & $87,66 \%$ & $637,69 \%$ \\
\hline PASSIVO NÃO-CIRCULANTE & $100 \%$ & $630,86 \%$ & $416,76 \%$ & $520,63 \%$ & $126,57 \%$ \\
\hline OBRIGAÇÕES DE LONGO PRAZO & $100 \%$ & $630,86 \%$ & $416,76 \%$ & $520,63 \%$ & $126,57 \%$ \\
\hline PATRIMONIO LÍQUIDO & $100 \%$ & $114,32 \%$ & $145,63 \%$ & $205,77 \%$ & $26,51 \%$ \\
\hline SOBRAS ACUMULADAS & $100 \%$ & $113,02 \%$ & $184,12 \%$ & $378,85 \%$ & $386,27 \%$ \\
\hline
\end{tabular}

Quadro 2 - Análise horizontal do passivo

Na Análise Horizontal do DSP os Ingressos Líquidos aumentaram de 133,17\% em 2011 para 372,17\% em 2014 enquanto que os Custos dos Ingressos apresentaram uma variação de $381,52 \%$ em 2014 . Os Ingressos Operacionais apresentaram aumento durante o período, porém houve uma pequena queda com relação a 2013 e 2014 de 25,54\%. Dentre as despesas, a que apresentou maior variação foram as Despesas Administrativas. Em 2011 a análise vertical era de $120,58 \%$ passando para $243,21 \%$ em 2014 enquanto que as Despesas Indedutíveis diminuíram de 71,39\% em 2011 para 45,96\% em 2014.
A conta Resultado de Provisões apresentou um aumento de $334,55 \%$ durante o período analisado, enquanto que o Resultado Financeiro variou $29,36 \%$ em 2011 passando para 125,74\% em 2014. Tanto o FATES quanto as Provisões apresentaram aumento no período, assim como o Fundo de Reserva. As Sobras Líquidas do Exercício apresentaram um significativo aumento de 2012 a 2013, passando de $184,12 \%$ para $378,85 \%$ e fechando o período com uma variação de $386,27 \%$. No quadro a seguir pode-se observar os valores da análise horizontal do DRE.

\begin{tabular}{|l|c|c|c|c|c|}
\hline & $\mathbf{A} / \mathbf{H} \mathbf{2 0 1 0}$ & $\mathbf{A} / \mathbf{H} \mathbf{2 0 1 1}$ & $\mathbf{A} / \mathbf{H} \mathbf{2 0 1 2}$ & $\mathbf{A} / \mathbf{H} \mathbf{2 0 1 3}$ & $\mathbf{A} / \mathbf{H} \mathbf{2 0 1 4}$ \\
\hline INGRESSOS LíQUIDOS & $100 \%$ & $149,78 \%$ & $168,65 \%$ & $292,82 \%$ & $372,17 \%$ \\
\hline CUSTO DOS INGRESSOS & $100 \%$ & $148,33 \%$ & $163,90 \%$ & $286,53 \%$ & $381,52 \%$ \\
\hline DISPÊNDIOS/INGRESSOS OPERACIONAIS & $100 \%$ & $165,08 \%$ & $222,61 \%$ & $333,01 \%$ & $307,47 \%$ \\
\hline Despesas Administrativas & $100 \%$ & $120,58 \%$ & $162,18 \%$ & $193,55 \%$ & $243,21 \%$ \\
\hline Despesas Indedutiveis & $100 \%$ & $71,39 \%$ & $98,19 \%$ & $41,78 \%$ & $45,96 \%$ \\
\hline Resultado de Provisões & $100 \%$ & $153,89 \%$ & $247,83 \%$ & $111,06 \%$ & $434,55 \%$ \\
\hline Resultado Financeiro & $100 \%$ & $29,36 \%$ & $43,49 \%$ & $93,69 \%$ & $125,74 \%$ \\
\hline Fundo de Reserva & $100 \%$ & $113,02 \%$ & $184,12 \%$ & $378,85 \%$ & $386,27 \%$ \\
\hline FATES & $100 \%$ & $102,59 \%$ & $136,84 \%$ & $188,19 \%$ & $246,81 \%$ \\
\hline Provisões & $100 \%$ & $101,32 \%$ & $142,88 \%$ & $181,27 \%$ & $282,84 \%$ \\
\hline SOBRAS LíQUIDAS DO EXERCíCIO & $100 \%$ & $113,02 \%$ & $184,12 \%$ & $378,85 \%$ & $386,27 \%$ \\
\hline
\end{tabular}

Quadro 3 - Análise horizontal do DRE 
Os resultados apresentados pela CAMSUL demonstram que a cooperativa está se desenvolvendo nos últimos anos e ampliando sua atuação no ramo. Por meio da análise dos cinco últimos períodos (2010 a 2014) foi possível averiguar os resultados apresentados pela cooperativa, bem como seu desempenho.

A cooperativa apresentou um aumento de mais de $416 \%$ no ativo circulante durante o período analisado, enquanto que o passivo circulante teve um crescimento de $405 \%$.

A análise dos índices de liquidez revelou que a cooperativa possui uma boa capacidade de pagamento a curto prazo e que possui condições de quitar suas dívidas com terceiros. No entanto, a maior parte de seus recursos está sendo financiada a curto prazo, o que não seria uma situação ideal, visto que o índice de liquidez imediata revelou que a cooperativa não seria capaz de quitar suas dívidas em curtíssimo prazo.

A análise dos índices de rentabilidade revelou que a cooperativa está cumprindo com seu papel para com o associado, ou seja, está revertendo as sobras em prol dos associados.

A análise dos índices de endividamento mostrou que a maior parte dos financiamentos da cooperativa estão sendo com recursos de terceiros e revelou dependência com relação a estes.

$\mathrm{Na}$ análise vertical das contas do Ativo, a conta Clientes apresentou aumento no decorrer do período, revelando que a cooperativa faz a maior parte de suas vendas a prazo. Isto justifica o porquê da maior parte de suas dívidas estarem em poder de terceiros.

Já na análise do Passivo, a conta Fornecedores também apresentou crescimento o que indica que a cooperativa aumentou suas obrigações a pagar.

Para finalizar, vale ressaltar que por mais que uma cooperativa não vise o lucro, a mesma não pode se omitir a buscar retorno para seus cooperados, e a CAMSUL cumpriu com seu dever, fazendo com que as sobras líquidas do exercício se mantivessem em constante aumento.

Sendo assim, pode-se considerar que a CAMSUL tem administrado com sabedoria e eficácia seus recursos, trazendo satisfação a seus cooperados.

\section{Declaração de Direito Autoral}

Declaramos que o presente artigo é original e não foi submetido à publicação em qualquer outro periódico nacional ou internacional, quer seja em parte ou na íntegra. Declaramos ainda, que após publicado pela Revista de Gestão e Organizações Cooperativas, ele jamais será submetido a outro periódico. Também temos ciência que a submissão dos originais à Revista de Gestão e Organizações Cooperativas implica transferência dos direitos autorais da publicação digital e impressa e, a não observância desse compromisso, submeterá o infrator a sanções e penas previstas na Lei de Proteção de Direitos Autorais ( ${ }^{\circ} 9610$, de 19/02/98).

\section{Política de Privacidade}

Os nomes e endereços informados nesta revista serão usados exclusivamente para os serviços prestados por esta publicação, não sendo disponibilizados para outras finalidades ou à terceiros.

\section{Conclusões}

Após a análise dos índices, ficou claro a importância da análise econômica financeira em cooperativas. Esta análise proporcionou um melhor entendimento acerca dos dados contábeis da CAMSUL.

Ao retomar a questão de pesquisa: Qual a situação econômica financeira da CAMSUL, de acordo com a análise das demonstrações contábeis dos últimos cinco anos? Pode-se inferir que a cooperativa encontrase com boa saúde financeira, embora economicamente, deixe um pouco a desejar.

Para chegar nessa conclusão, percorreu-se a seguinte trajetória: i. Revisão bibliográfica acerca dos principais conceitos utilizados para a análise financeira das organizações; ii. Cálculo dos índices econômico-financeiros mais utilizados contabilmente; e, iii. Análise da situação econômica-financeira da cooperativa, com base nos índices já calculados.

Durante o desenvolvimento do trabalho, detectaram-se algumas limitações de pesquisa, como a escassez de bibliografia específica sobre a análise econômica financeira de cooperativas, o que restringiu a pesquisa pela falta de maiores informações a respeito do tema escolhido.

Diante disso, pode-se recomendar para estudos futuros a correção monetária das demonstrações, tornando a análise mais fidedigna e a comparação com outras cooperativas do mesmo ramo.

Essa pesquisa ainda pode ser complementada pela adoção de modelos de análise que quantifique a saúde financeira da cooperativa. 


\section{Referências}

BIALOSKORSKI NETO, S. Cooperativas: economia, crescimento e estrutura de capital. 1998. Tese (Doutorado em Economia Aplicada) - Universidade de São Paulo, Piracicaba, 1998.

BRAGA, M. J. Avaliação financeira das cooperativas de crédito mutuo do estado de minas gerais. 2002. Disponível em <www.sober.org.br>. Acesso em 21 de out, 2015.

BRASIL, Lei $n^{\circ}$. 5.764, de dezembro de 1971. Define a Política Nacional de Cooperativismo, institui o regime jurídico das sociedades cooperativas e de outras providencias. Disponível em: <www.ocb.org.br>. Acesso em 01 set, 2015.

CAMSUL - A CAMSUL. Disponível em: $<$ http://camsul.com.br/site/a-camsul/>. Acesso em 03 ago, 2015.

CARVALHO, C. T. Análise dos demonstrativos contábeis - Índices de Endividamento. Belém. 2003. Acesso em 29 de out, 2015.

CATAPAN, A. E. CATAPAN, A. CATAPAN, C. D. VEIGA, P. C. ABIB, M. Análise das demonstrações contábeis como etapa preliminar para elaboração do planejamento de curto, médio e longo prazo no Brasil: Um estudo de caso na Votorantim Cimentos. Espacios. Vol. 36. 2015.

CHING, Y. H. Contabilidade e finanças para não especialistas. 3 ed. São Paulo. 2010.

COSSERMELLI, B. C. - A utilização de índices de liquidez e rentabilidade na análise da gestão do desenvolvimento empresarial. UNISEPE, 2014.

DENACOOP. Evolução do Cooperativismo no Brasil. Ministério da Agricultura, Pecuária e Abastecimento. Brasília. MAPA. 2006.

FREITAS, D. C. Índice de Endividamento. Universidade Federal do Pará. Disponível em $<$ http://peritocontador.com.br/>. Acesso em $29 \mathrm{de}$ out, 2015.
GIL, A. C. - Como elaborar projetos de pesquisa, $5^{\text {a }}$ edição. Atlas, 2012. VitalBook file.

GITMAN, L. J. Princípios de Administração Financeira. $7^{\text {a }}$ ed. São Paulo. Ed. Harbra, 1997.

KERLINGER, F. N. - Metodologia da pesquisa em ciências sociais. São Paulo. Editora da Universidade de São Paulo. 1980.

MATARAZZO, Dante Carmine. Análise Financeira de Balanços: Abordagem básica e gerencial. 3a. Ed. São Paulo: Atlas, 1998. p. 29.

MINISTÉRIO DA AGRICULTURA - Cooperativismo e Associativismo. Brasília. 2012. Disponível

em:

<http://www.agricultura.gov.br/cooperativismoassociativismo/cooperativismo>. Acesso em $10 \mathrm{de}$ set, 2015.

MOURA, D. C. Moral Hazard na relação contratual entre cooperativa e cooperado. Revista de Contabilidade e Organizações. Vol. 2. Universidade de São Paulo. 2008.

MOURA, O. R. Estrutura e análises de balanços fácil. $8^{a}$ ed. São Paulo. Saraiva, 2009.

OCB. Organização das Cooperativas do Brasil. Disponível em: <http://www.agricultura.gov.br/ >. Acesso em 08 de set, 2015.

OCB. Cooperativismo, evolução no Brasil. Disponível

em:<http://www.ocb.org.br/site/cooperativismo/ev olucao_no_brasil.asp >. Acesso em 10 de set, 2015.

PEREIRA, A.C. Contribuição à análise e estruturação das demonstrações financeiras das sociedades cooperativas brasileiras: Ensaio de abordagem social. Contab. Vista e Rev. Belo Horizonte, v. 6, n. 1, p. 33-41. Dez. 1995.

PORTAL DA CONTABILIDADE - Normas Brasileiras de Contabilidade. Disponível em <http://www.portaldecontabilidade.com.br/nbc/t10 8it01.htm>. Acesso em 05 set, 2015. 
PORTAL DO COOPERATIVISMO DE CRÉDITO -

Disponível em

<www.cooperativismodecredito.coop.br>. Acesso em 21 de out, 2015.

SILVA, ABRANTES E OLIVEIRA - Doutrina e princípios cooperativistas: Um estudo de caso na cooperativa Maxi Mundi. Revista científica do ITPAC, Araguaína. Julho, 2012.

SILVA, G. D. Índices Financeiros e Lucratividade Um estudo dos índices de rentabilidade. UFPA. 2007.

SOUZA, V. S. MOREIRA, L. H. Liquidez. A saúde financeira das empresas. UFPA. 2003.

VERGARA, S. C. - Projetos e relatórios de pesquisa em administração. $15^{a}$ edição. - São Paulo: Atlas, 2014.

VIEIRA, H. B. C. VERDE, L. O. I BEZERRA, L. R. RODRIGUES, N. P. ISMAEL, S. V. Índices de Rentabilidade - Um estudo sobre os indicadores ROA, ROI e ROE de empresas do subsetor de tecidos, calçados e vestuários listados na BOVESPA. Congresso Virtual Brasileiro de Administração. 2011.

Análise Financeira de Balanços: abordagem básica e gerencial. 5a. Ed. São Paulo: Atlas, 1998.

OCB - ORGANIZAÇÃO E SINDICATO DAS COOPERATIVAS BRASILEIRAS. Áreas de atuação prioritárias. Disponível em < http://www.ocb.org.br/site/sescoop/ atuação.asp > Acesso 24 jan. 2014. 
